7th International Symposium on Superalloy 718 and Derivatives Edited by: E.A. Ott, J.R. Groh, A. Banik, I. Dempster, T.P. Gabb, R. Helmink, X. Liu, A. Mitchell, G.P. Sjöberg, and A. Wusatowska-Sarnek TMS (The Minerals, Metals \& Materials Society), 2010

\title{
Hold-Time Fatigue Crack Growth of Allvac 718Plus
}

\author{
Magnus Hörnqvist ${ }^{1}$, Leif Viskari ${ }^{2}$, Krystyna Stiller $^{2}$, Göran Sjöberg ${ }^{1}$ \\ ${ }^{1}$ Materials Technology, Volvo Aero Corporation, \\ Trollhättan, S-46181, Sweden \\ ${ }^{2}$ Department of Applied Physics, Chalmers University of Technology, \\ Göteborg, S-41296, Sweden.
}

Keywords: Fatigue crack growth; Tensile dwell; Electron microscopy; Fractography

\begin{abstract}
The hold-time fatigue behaviour of Allvac 718Plus was investigated both in the as-heat treated condition and after long-time exposure at temperature close to the maximum operating limit. At temperatures above $450^{\circ} \mathrm{C}$ the introduction of $90 \mathrm{~s}$ hold-time at maximum load significantly increased the fatigue crack growth rate. Both conditions showed purely cycle dependent behavior at $450^{\circ} \mathrm{C}$ and close to purely time dependent behavior at $700^{\circ} \mathrm{C}$. At $600^{\circ} \mathrm{C}$ intermediate behavior was observed. The long-time exposure had little effect on the cyclic $(0.5 \mathrm{~Hz})$ crack growth rates, but the resistance to crack growth with $90 \mathrm{~s}$ hold-time decreased. No microstructural effects of long-time exposure $\left(700^{\circ} \mathrm{C} / 140 \mathrm{~h}+675^{\circ} \mathrm{C} / 460 \mathrm{~h}\right)$ could be observed by SEM, but there were indications that the hardness of the material increases somewhat after exposure.
\end{abstract}

\section{Introduction}

For many years research activities have been carried out to meet the requirements for an alloy with a temperature capacity above the $650^{\circ} \mathrm{C}$ limit for the standard Alloy 718 and with the same strength levels and also with the same easiness by which the grain size can be monitored through metallurgical processing (see e.g. [1] for a summary). For various reasons these research efforts have been met with limited success - the versatility of Alloy 718 is in fact very difficult to balance. Waspaloy is the traditional natural choice for components to be used at temperature above the limit for Alloy 718. However, the strength of Waspaloy is much lower and due to its very fast $\gamma^{\prime}$ precipitation hardening response it is a difficult alloy to process. Allvac 718Plus is in fact a promising alloy that fits remarkably well between the standard Alloy 718 and Waspaloy and with many of the benefits of Alloy 718 preserved [1,2]. Like Alloy 718 it exhibits $\delta$-phase as a secondary phase which allows for grain size control and also exhibits a similar retarded hardening response irrespective of its $\gamma$ ' hardening characteristics which opens up for a similar versatility.

One of the major challenges, however, not least for an alloy intended for disk applications, is to master the notch sensitivity at the higher temperature ranges. This means that the environmentally induced grain boundary embrittlement must be controlled [3]. Since this type of embrittlement increases rapidly with temperature it is a major issue in launching a promising alloy for higher temperature applications. The critical mechanical property which is the stumbling block is then the crack growth under sustained load or during fatigue loading with tensile hold times - the hold-time fatigue - which is the topic of the present study. 
Previous results on Allvac 718Plus have shown that the alloy is sensitive to hold-time fatigue, although less so than alloy 718 , and that grain size significantly influences the hold-time crack growth resistance [4-6]. The presence of $\delta$-phase at the grain boundaries has been shown to be beneficial as compared to clean grain boundaries [7], but recent results have indicated that the fraction and distribution of the precipitates are not critical for controlling the properties [8, 9]. The present study aims to investigate the crack growth in Allvac 718Plus at temperatures in the range 450 to $700^{\circ} \mathrm{C}$ with and without hold-times. Furthermore, the effects of long time exposure in the upper design temperature range are investigated.

\section{Experimental}

\section{$\underline{\text { Material }}$}

The composition of the investigated material is given in Table 1 . The ring from which the material was taken was forged in several steps with intermediate heating at $1100^{\circ} \mathrm{C}$ during the initial rolling steps and $1010^{\circ} \mathrm{C}$ during later rolling steps. The thermal history resulted in a grain size of ASTM 5 and grain boundaries with insufficient amount of $\delta$-phase. Therefore, to attain the desired grain boundary structure, the following heat treatment was applied: $870^{\circ} \mathrm{C} / 16 \mathrm{~h} / \mathrm{AC}+$ $970^{\circ} \mathrm{C} / 1 \mathrm{~h} / \mathrm{WQ}+788^{\circ} \mathrm{C} / 8 \mathrm{~h} / \mathrm{AC}+704^{\circ} \mathrm{C} / 8 \mathrm{~h} / \mathrm{AC}$, where the initial pre-solution soaking is included to aid precipitation of grain boundary $\delta$.

To investigate the effect of long-time exposure to harsh service conditions, a number of specimens from each material were subjected to a second heat treatment cycle consisting of $140 \mathrm{~h}$ at $700^{\circ} \mathrm{C}$ and $460 \mathrm{~h}$ at $675^{\circ} \mathrm{C}$. This treatment is supposed to mimic in-service exposure in a typical temperature range where Allvac 718Plus could be considered as replacement for Alloy 718. Hereafter the as-heat treated material will be referred to as A and the exposed as E in figure legends etc.

\section{Mechanical testing}

From the forged rings, specimens for fatigue crack growth testing were cut in the axial direction. The specimens were of the Kb-type, schematically shown in Fig. 1(a), with a gage length cross section of $4.3 \times 10.2 \mathrm{~mm}$. A starter notch of nominal depth $\left(a_{\mathrm{n}}\right.$ according to Fig. 1(b)) of 0.075 $\mathrm{mm}$ and total width $\left(c_{\mathrm{n}}\right)$ of $0.15 \mathrm{~mm}$ was electric discharge machined. The crack size was monitored using the direct current potential drop (DCPD) technique [10] by spot welding probes close to the notch at either side. Additional probes were spot welded on the back face of the specimen, away from the cross-section containing the starter notch.

As the specimen was mounted a DC current of $10 \mathrm{~A}$ was run through the sample and the resulting potential drop (PD) was amplified and recorded by the system. The PD signal measured over the notch, and later crack, was divided by the reference signal from the back face probes and translated to crack length by a calibration function assuming a semi-circular crack.

Table 1. Composition of the forged Allvac 718Plus ring in weight per cent.

\begin{tabular}{|c|c|c|c|c|c|c|c|c|c|c|c|}
\hline $\mathrm{Ni}$ & $\mathrm{Cr}$ & $\mathrm{Mo}$ & $\mathrm{W}$ & $\mathrm{Co}$ & $\mathrm{Fe}$ & $\mathrm{Nb}$ & $\mathrm{Ti}$ & $\mathrm{Al}$ & $\mathrm{C}$ & $\mathrm{P}$ & $\mathrm{B}$ \\
\hline Bal. & 17.9 & 2.7 & 1.0 & 9.0 & 9.5 & 5.5 & 0.8 & 1.4 & 0.02 & 0.01 & 0.004 \\
\hline
\end{tabular}




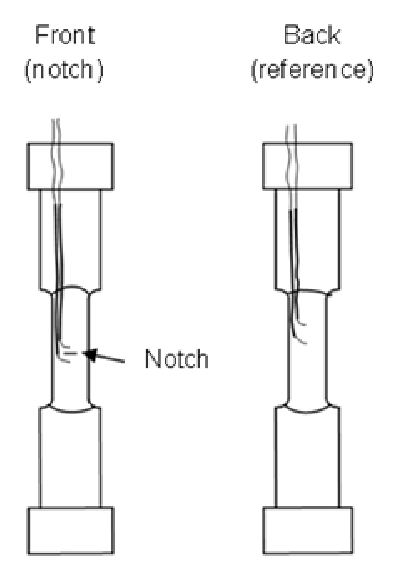

(a)

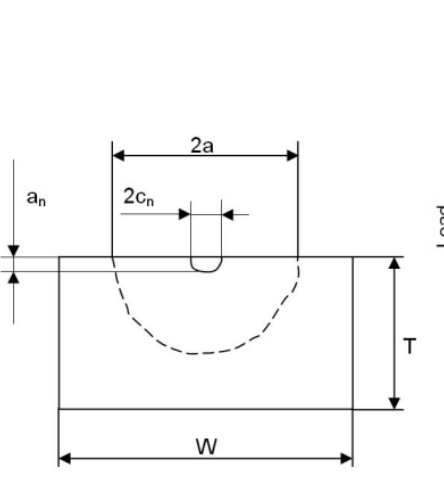

(b)

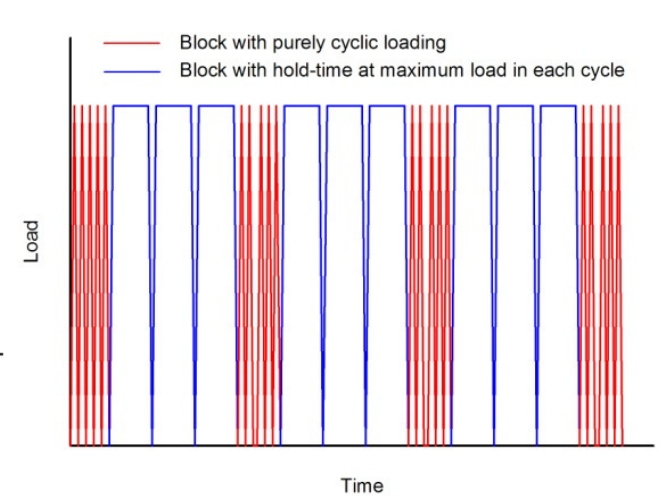

(c)

Figure 1. (a) Sketch of the Kb-type specimen used in the study, including the PD probes at the notch and reference probes at the back of the specimen. (b) Cross-section at the crack plane showing the initial starter notch and fatigue crack. (c) Schematic representation of the applied loading sequence consisting of blocks with purely cyclic loading mixed with blocks where a hold-time was applied at maximum load at each cycle (see text for details).

A pre-crack of depth around $0.3-0.4 \mathrm{~mm}$ was generated at a load ratio $R=0.05$ at room temperature, after which the specimen was heated to the required test temperature. Following temperature stabilization the test was started. Tests with purely cyclic and mixed (cyclic and hold-time) loading were carried out at $450^{\circ} \mathrm{C}, 600^{\circ} \mathrm{C}$ and $700^{\circ} \mathrm{C}$. Purely cyclic (base-line) tests were performed at $0.5 \mathrm{~Hz}$ and an $R$-ratio of 0 . The tests with mixed loading consisted of several blocks with either purely cyclic loading or cycles with a hold-time at maximum load, as schematically shown in Fig. 1(c). All cycles had an $R$-ratio of 0 . The purely cyclic blocks were conducted with of $0.5 \mathrm{~Hz}$, as for the base-line tests, and the hold time cycles had a trapezoidal waveform with a $1 \mathrm{~s}$ loading ramp, $90 \mathrm{~s}$ hold-time and $1 \mathrm{~s}$ unloading ramp. The tests were designed so that each hold-time block should give a total crack length increment of approximately 0.1-0.2 mm. During testing, data (time, cycle, maximum load, minimum load, PD signal and reference PD signal) was recorded every ten cycles during cyclic loading and at each cycle for he hold-time blocks, and post-test filtered using an 11-point running average. The calculated crack lengths were rounded to $0.01 \mathrm{~mm}$ (nominal resolution of the DCPD technique) and the average cycle number corresponding to each rounded crack length were calculated. The evaluation of the tests was made by calculating stress intensity factor range, $\Delta K$, according to [10] assuming a semi-circular crack, and the fatigue crack growth rate $\mathrm{d} a / \mathrm{d} N$ according to the secant method in [11].

\section{Electron Microscopy}

Microstructural investigations were performed on the $\mathrm{A}$ and $\mathrm{E}$ conditions without effect of testing. Fractographic analyses were performed on both conditions on samples tested at $600^{\circ} \mathrm{C}$ and $700^{\circ} \mathrm{C}$ as these were clearly showing effects of hold-times in terms of mechanical data.

All microstructural and fractographic investigations were performed using a FEI Quanta 200 field-emission gun (FEG) scanning electron microscope (SEM) at $20 \mathrm{kV}$ acceleration voltage. Oxford INCA energy dispersive X-ray (EDX) spectroscopy system was used for elemental analysis and phase identification. Secondary electron (SE) and backscattered electron (BSE) 
imaging modes were used. For microstructural analyses, backscattered electron (BSE) was primarily used, allowing for monitoring of secondary phases. For fractographical analyses, Secondary electron (SE) mode was used for detailed imaging. Furthermore, BSE was used to differentiate between hold-time and cyclic loading as these two fracture modes result in differing contrasts (darker for hold time and brighter for cyclic loading), described in a previous study [7].

Samples for microstructural studies were excised from the grips of the mechanical testing specimens, as the grips are not exposed to high temperatures. The specimens were ground and polished to 1um grit finish. Samples used for EDX analysis were not etched, however, for samples used for imaging purposes light etching using Kallings no 2 reagent was applied. Final fracture of specimens for fractographic analyses was performed by bending at room temperature.

\section{Results}

\section{$\underline{\text { Microstructures }}$}

Microstructural investigations by SEM (Fig. 2) show the A and E conditions to be similar. The grain size in both conditions was estimated to ASTM 3 and extensive twinning was observed as a result of the thermo-mechanical history. $\delta$-phase precipitates were found at grain and twin boundaries, but also in the grain interiors at what seem as pre-grain-growth grain boundaries. In a number of twin boundaries $\delta$-phase has a film-like appearance throughout vast lengths (in some instances spanning through the entire grain), similar to MC-carbide grain boundary films. Other phases observed in SEM were randomly distributed $\mathrm{Nb}$ - and Ti-carbides, some micrometer in size. Hardening precipitates in bulk samples of this alloy cannot readily be analyzed by SEM technique and are not considered here.

No clear changes in the microstructure due to the long-time exposure could be observed by the applied techniques. Hardness measurements by Vickers 10kg (HV10) at room temperature showed little difference between the two conditions. For both conditions the measured hardness ranged from 421 to 464 HV10, although the mean values differed slightly (437 HV10 in the A condition compared to $450 \mathrm{HV} 10$ in the exposed condition).
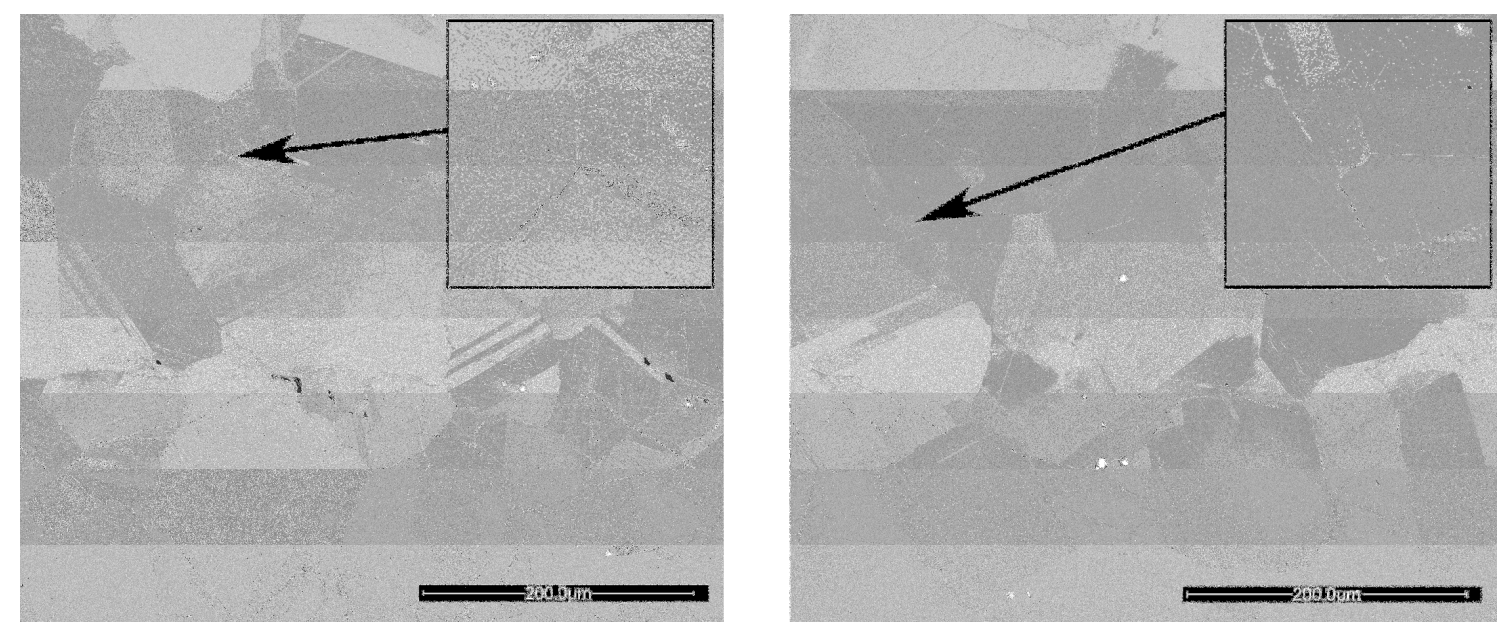

Figure 2. SEM BSE images of the as-heat-treated (left) and exposed (right) conditions. Inserts show 4:1 enlargements of selected regions, exemplifying distribution of $\delta$-phase precipitates. 

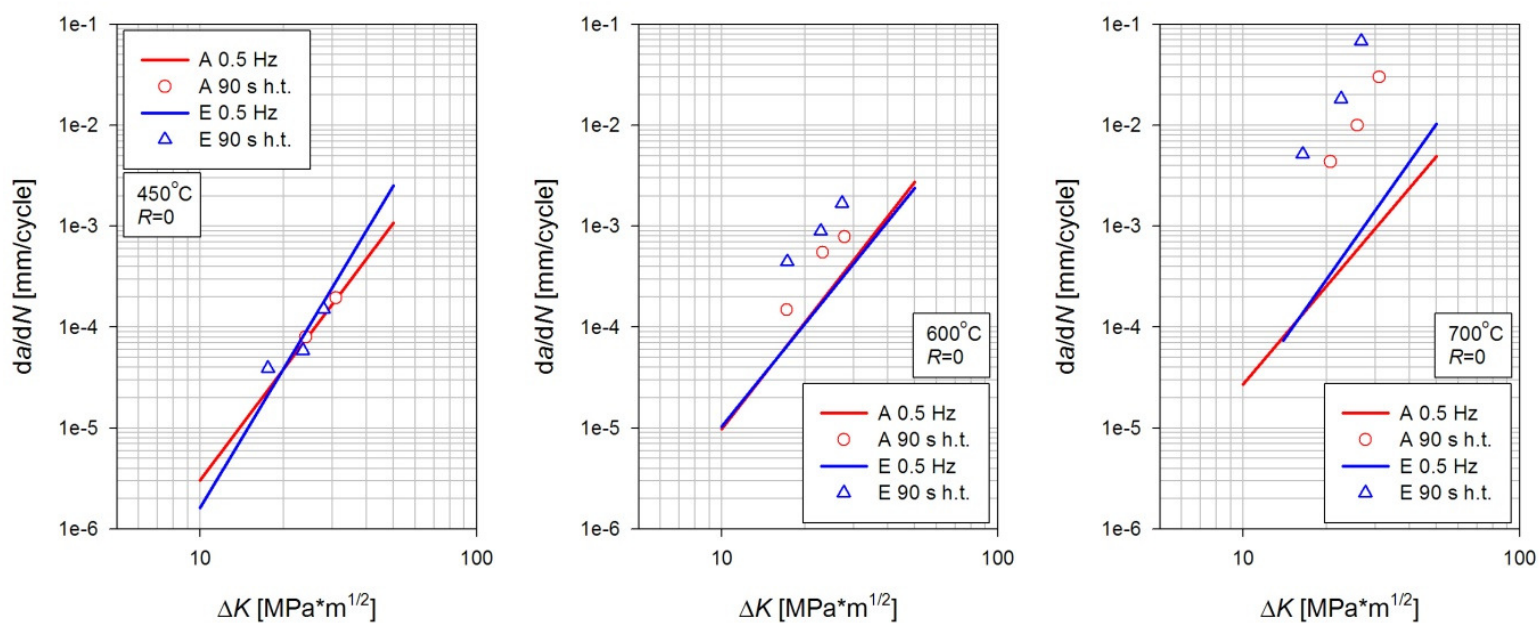

Figure 3. Fatigue crack growth rate per cycle $(\mathrm{d} a / \mathrm{d} N)$ for $0.5 \mathrm{~Hz}$ loading and $90 \mathrm{~s}$ hold time at 450,600 and $700^{\circ} \mathrm{C}$.
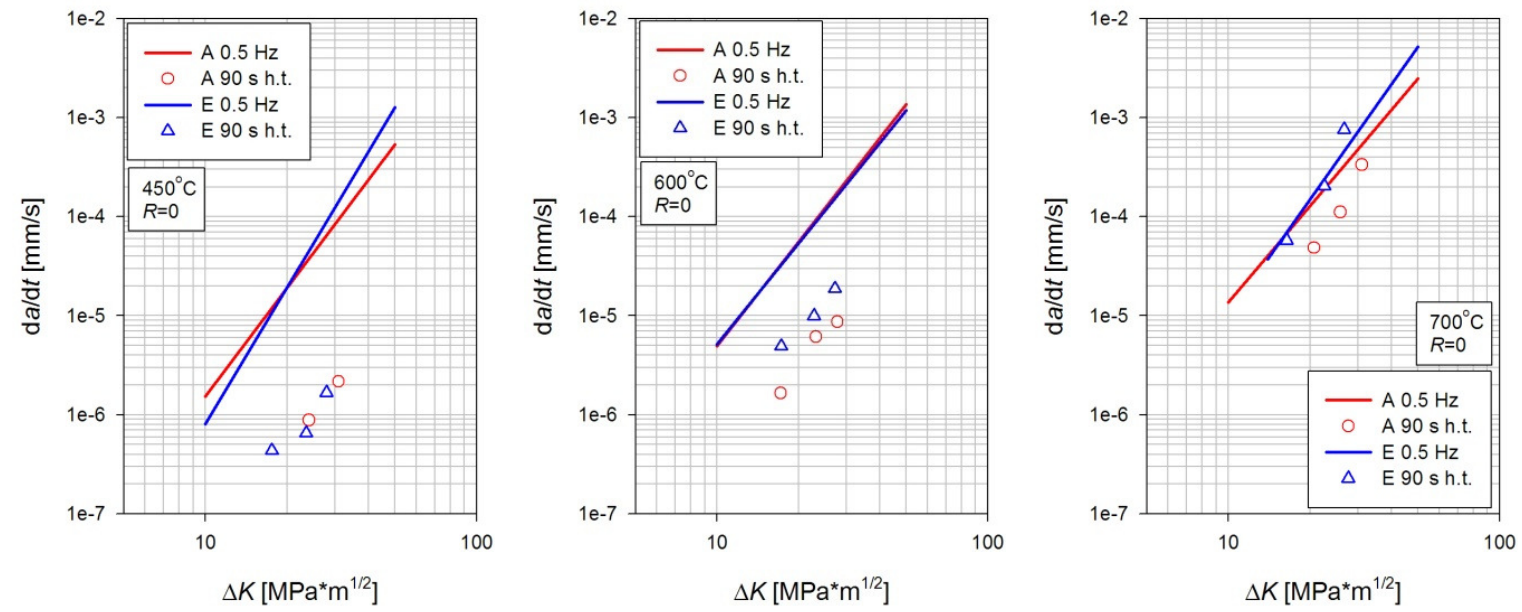

Figure 4. Fatigue crack growth rate per time $(\mathrm{d} a / \mathrm{d} t)$ for $0.5 \mathrm{~Hz}$ loading and $90 \mathrm{~s}$ hold time at 450, 600 and $700^{\circ} \mathrm{C}$.

\section{$\underline{\text { Hold-Time Fatigue Crack Growth }}$}

Figures 3 and 4 show the results from the FCG tests. The base-line data is presented as linear regressions of data from two identical tests and for the mixed tests only the data from the holdtime blocks is presented. There is a varying amount of scatter in the data from the hold-time blocks, which is generally larger than in purely cyclic testing. For easier viewing, the hold-time data is presented here as the average over each hold-time block based on the mean values of $a$, $\Delta K$ and $\mathrm{d} a / \mathrm{d} N$ obtained from the analysis. At $450^{\circ} \mathrm{C}$ there is no effect of hold-time or long-time exposure on the FCG behavior, but with increasing temperature the effect of hold-times becomes more pronounced and there is a detrimental effect of the long-time exposure (Fig. 3). If the results are viewed in terms of $\mathrm{d} a / \mathrm{d} t$ instead (Fig. 4), obtained by dividing $\mathrm{d} a / \mathrm{d} N$ with the cycle time, it can be seen that the propagation rate decreases when a hold-time is applied for 450 and $600^{\circ} \mathrm{C}$. At $700^{\circ} \mathrm{C}$, on the other hand, $\mathrm{d} a / \mathrm{d} t$ is roughly independent of cycle time. 

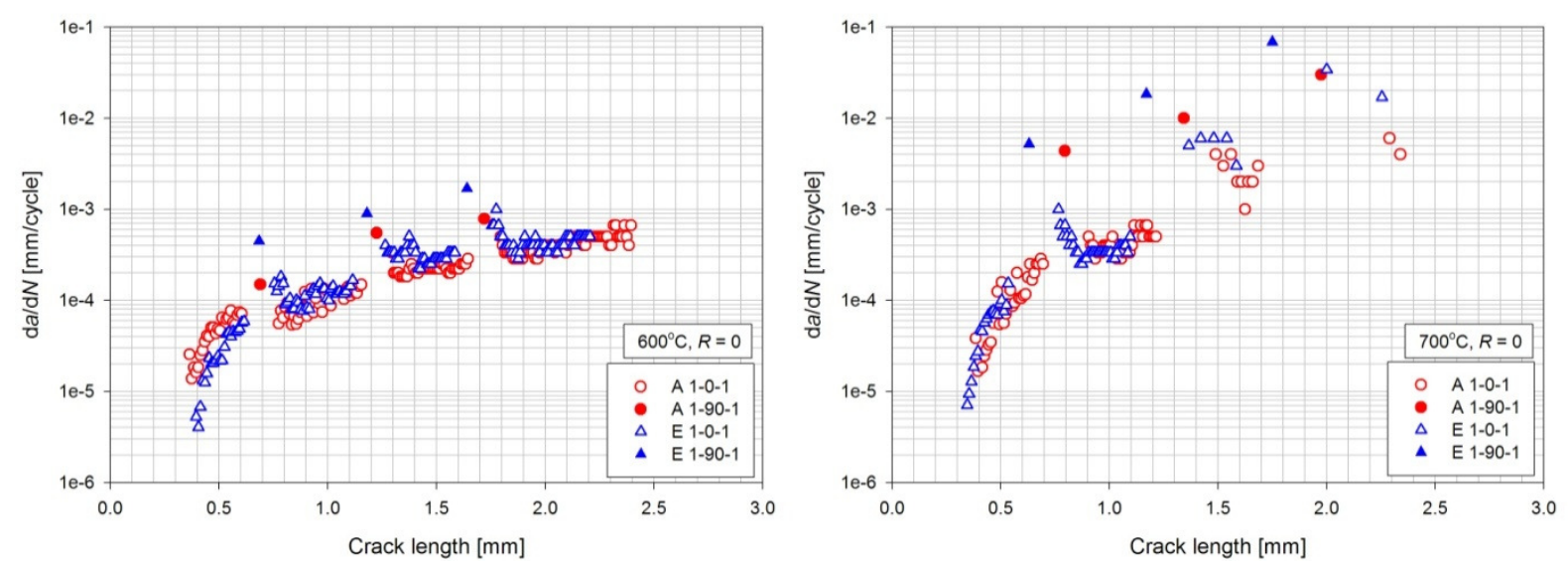

Figure 5. Fatigue crack growth rate as a function of crack length for Allvac 718Plus from tests with block loading.

\section{$\underline{\text { Transient effects }}$}

In Figure 5, the FCG rates for both cyclic and hold-time blocks from the tests with mixed loading at 600 and $700^{\circ} \mathrm{C}$ are plotted as a function of crack length $a$. Here it can be seen that 718Plus exhibits a gradual decrease, a transient, in the FCG rate when $0.5 \mathrm{~Hz}$ cycling is resumed after a hold-time block. The transients in the A condition are only observed at $700^{\circ} \mathrm{C}$ after hold-time block applied at crack lengths over around $1 \mathrm{~mm}$. In the $\mathrm{E}$ condition on the other hand, the transients occur at all crack lengths at both 600 and $700^{\circ} \mathrm{C}$, and the length of the transition zone increases with crack length and temperature. At $450^{\circ} \mathrm{C}$ the $\mathrm{FCG}$ rate is un-affected by the holdtime, as shown in Figs. 3 and 4, and consequently no transients are observed. The gradual decrease in FCG rate indicates that the hold time cycles have induced a permanent damage ahead of the crack tip which affects the FCG rate during purely cyclic loading as the crack grows through the damaged zone. The E condition appears to be more sensitive to hold-time induced damage.

\section{Fractography}

Figure 6 shows full length (though laterally limited) SEM BSE images of high temperature crack surfaces for both A and E conditions tested at 600 and $700^{\circ} \mathrm{C}$ respectively. Half the notch of each sample is seen in the bottom-left corner in the respective images, from which the crack has propagated to the final room-temperature fracture at the top end of the images. Dark radial areas, corresponding to fractured surfaces during hold-time loading, are clearly visible for the A condition tested at $600^{\circ} \mathrm{C}$ while such a contrast is less pronounced for the $\mathrm{E}$ condition. At $700^{\circ} \mathrm{C}$ the A condition allowed vague distinction of the second and third hold-times while for the exposed condition no obvious observations of this nature could be made.

The crack lengths calculated from measured PD values are based on the equivalent area of an assumed semi-circular crack, and the very irregular crack front observed in the present case makes it difficult to relate the positions on the fracture surface regions directly to the mechanical data with precision. It should also be noted that the fracture surfaces from the cyclic regions may not be fully representative of purely cyclic fatigue crack growth, as indicated by the transient behaviour observed after a hold-time block (see Fig. 5). 

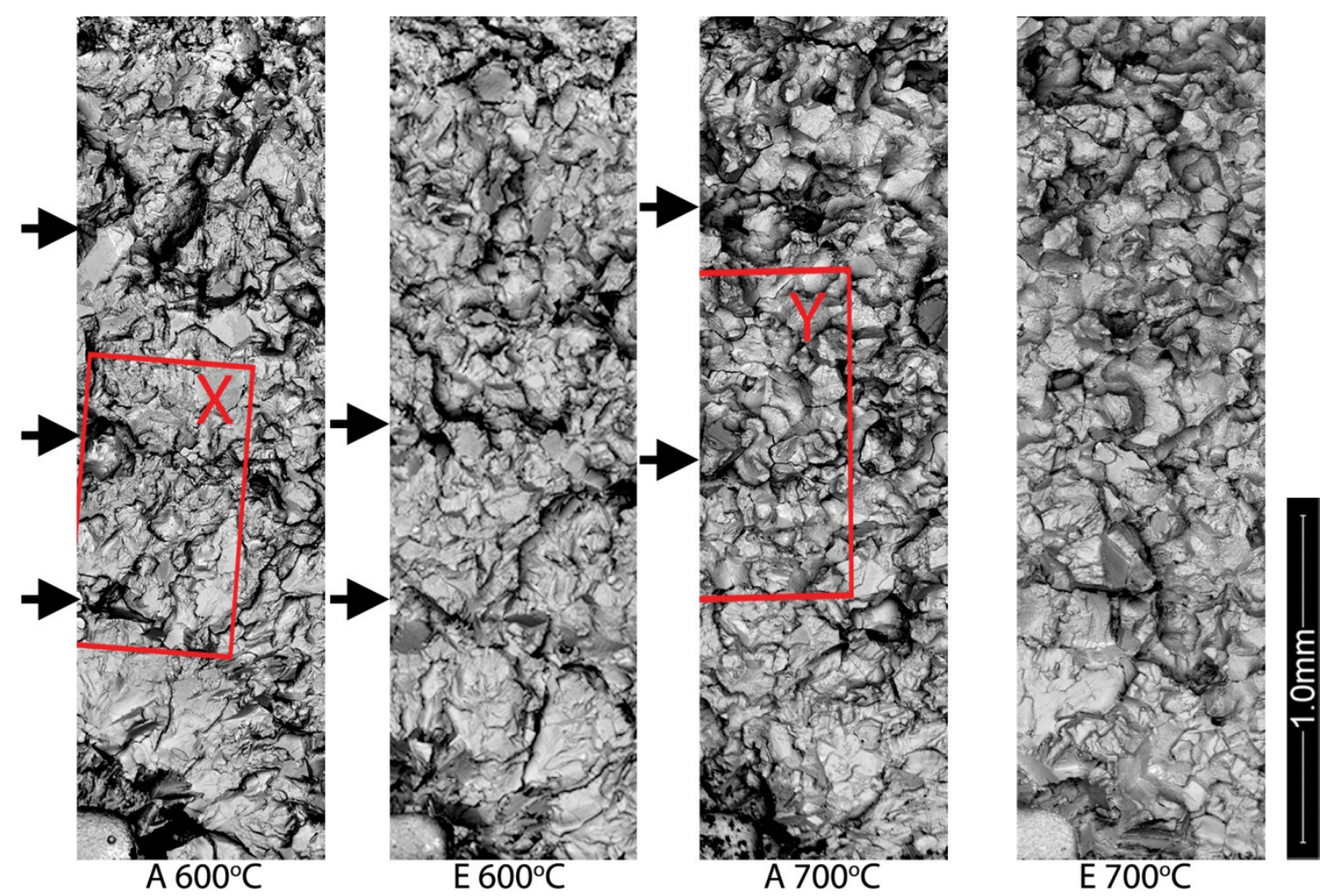

Figure 6. SEM BSE images showing crack surface overviews of A and E conditions tested at 600 and $700^{\circ} \mathrm{C}$. Enlargements of regions $\mathrm{X}$ and $\mathrm{Y}$ are shown in Figures 7 and 8, respectively. Arrows are added to aid in identification of dark hold-time zones, where clearly identifiable.

Figure 7 shows the fracture surface of condition A tested at $600^{\circ} \mathrm{C}$ in higher magnification (region $\mathrm{X}$ in Fig. 6). Images taken in SE and BSE modes are shown as they provide different contrast. The A condition showed extensive cleavage cracking in cyclic regions, increasing with crack length. Intergranular secondary cracking and also cracking of pre-grain-growth grain boundaries (decorated by $\delta$-phase) were observed in hold-time regions for both conditions. The $\mathrm{E}$ condition showed a generally more intergranular type of fracture following the first hold-time and less cleavage during cyclic loads. In both conditions, hold-time fracture appeared more faceted with increased crack path deviation from the load-orthogonal plane. These phenomena increased with the crack length

Higher magnification SE and BSE images of the A condition tested at $700^{\circ} \mathrm{C}$ are shown in Fig. 8 (region $\mathrm{Y}$ in Fig. 6). Both $\mathrm{A}$ and $\mathrm{E}$ conditions exhibited mainly transgranular fracture during the first cyclic block at $700^{\circ} \mathrm{C}$. However, aside from cleavage, fracture was mainly intergranular from the introduction of the first hold-time block and throughout the remainder of the crack. As for $600^{\circ} \mathrm{C}$, hold-time regions were found more faceted and to have greater deviation of crack path than the cyclic regions. However, at $700^{\circ} \mathrm{C}$ also the cyclic regions were mainly intergranularly fractured, although with less faceting crack path deviation than hold-time regions. It could also be discerned that for the A condition the differences between cyclic and hold-time regions in these aspects were more pronounced than for the exposed condition. Extensive secondary cracking of both new and pre-grain-growth boundaries was observed for the intergranular crack regions in both conditions. 

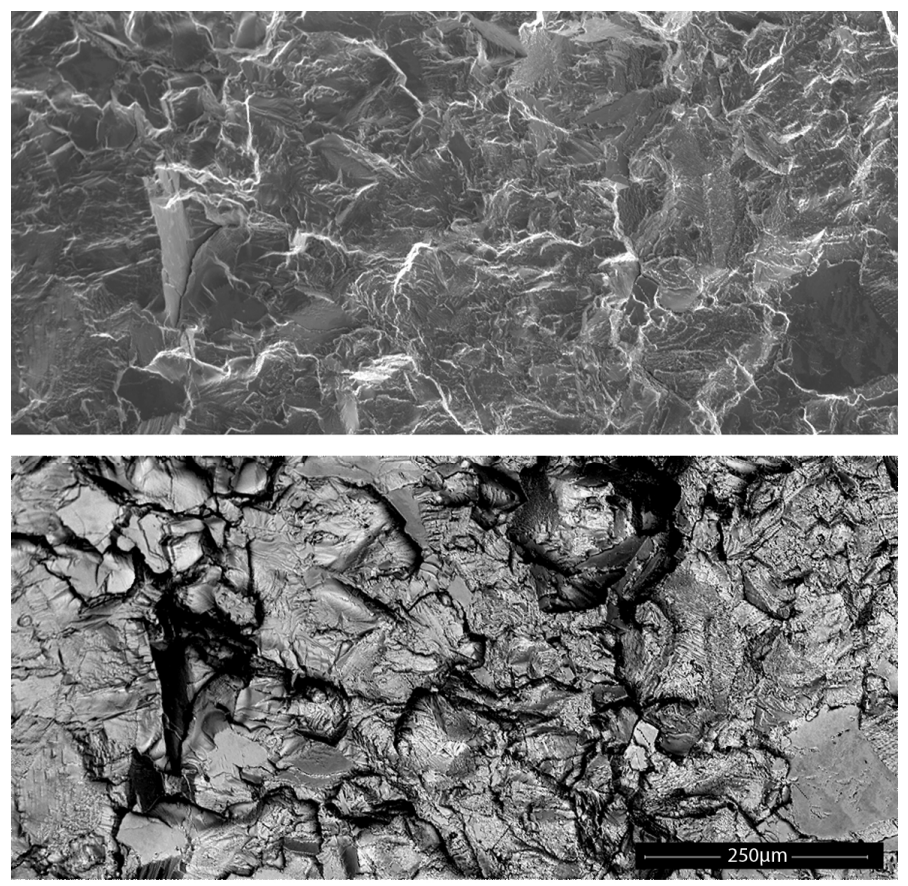

$\mathrm{H}$

C

$\mathrm{H}$

Figure 7: SEM BSE (above) and SE (below) images of condition A tested at $600^{\circ} \mathrm{C}$ (region $\mathrm{X}$ in Fig. 6). Crack propagation has occurred from left to right in the images. The above annotations $\mathrm{H}$ and $\mathrm{C}$ correspond to hold-time regions and cyclic regions, respectively.
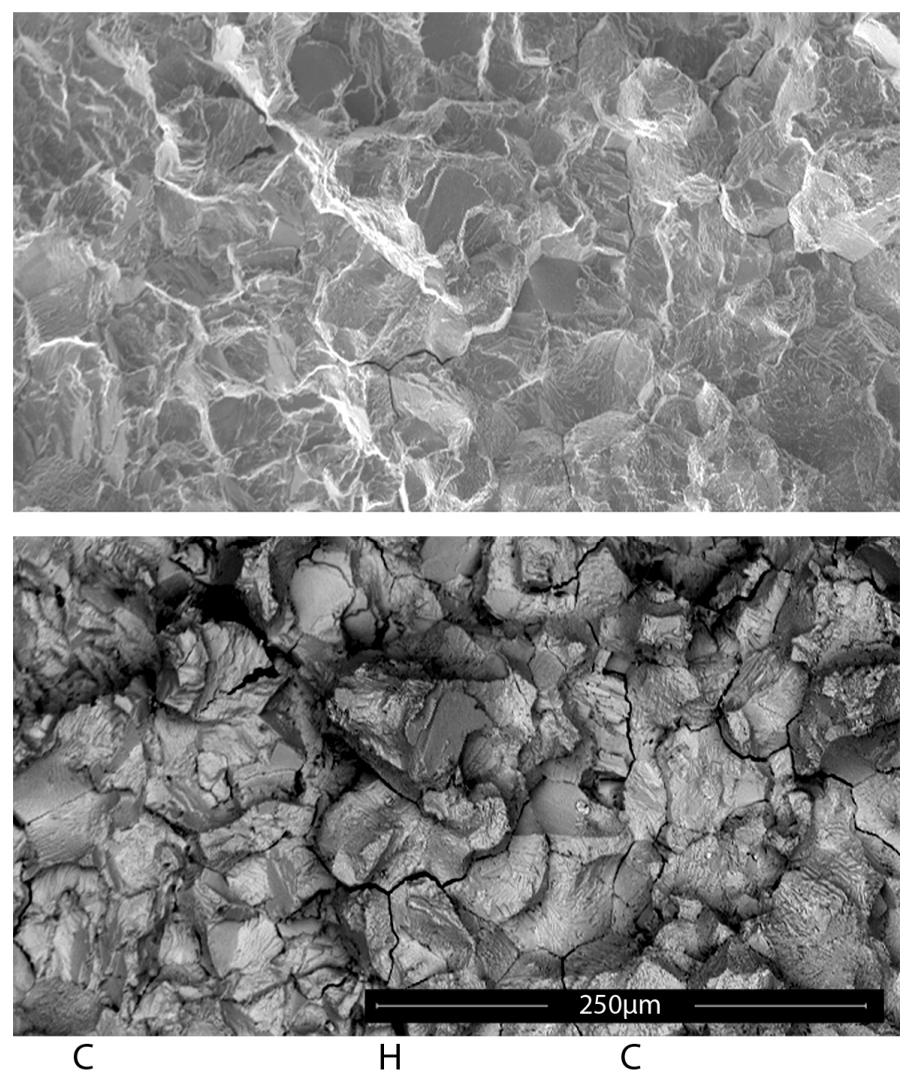

Figure 8: SEM BSE (above) and SE (below) images of condition A tested at $700^{\circ} \mathrm{C}$ (region $\mathrm{Y}$ in Fig. 6). Crack propagation has occurred from left to right in the images. The above annotations $\mathrm{H}$ and $\mathrm{C}$ correspond to hold-time regions and cyclic regions, respectively. 

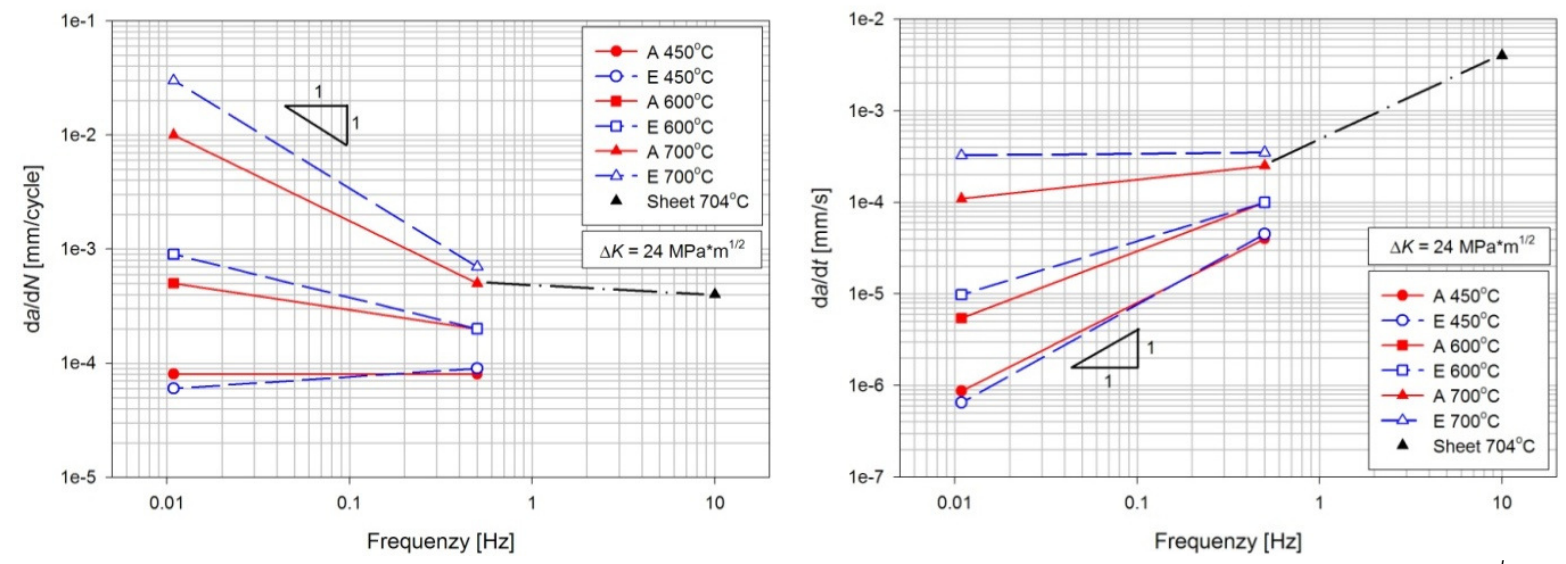

Figure 9. Fatigue crack growth rate per cycle $(\mathrm{d} a / \mathrm{d} N)$ and time $(\mathrm{d} a / \mathrm{d} t)$ at $\Delta K=24 \mathrm{MPa} \sqrt{\mathrm{m}}$ as a function of frequency. The unit slope corresponds to purely cycle and time dependent behavior. The data for Allvac 718Plus sheet material is from [7].

\section{Discussion}

\section{Effect of hold-times and exposure}

Figure 9 shows a summary of the frequency and temperature dependence of the FCG rate in terms of $\mathrm{d} a / \mathrm{d} N$ and $\mathrm{d} a / \mathrm{d} t$ at $\Delta K=24 \mathrm{MPa} \vee \mathrm{m}$. Also included in these figures are $10 \mathrm{~Hz}$ cyclic data from testing of Allvac 718 Plus sheet material at $704^{\circ} \mathrm{C}$ [7]. Here it can be clearly seen that the behavior changes from purely cycle dependent at $450^{\circ} \mathrm{C}$ to purely time dependent at $700^{\circ} \mathrm{C}$, with intermediate behavior at $600^{\circ} \mathrm{C}$. At $700^{\circ} \mathrm{C}$ the transition frequency is in the $0.1 \mathrm{~Hz}$ region, whereas the transition occurs below $0.01 \mathrm{~Hz}$ at $450^{\circ} \mathrm{C}$ and further testing would most likely reveal a limit somewhere between 0.01 and $0.1 \mathrm{~Hz}$ at $600^{\circ} \mathrm{C}$. This is consistent with literature results from e.g. [12-14], showing transition frequencies in the range of 0.1 to $1 \mathrm{~Hz}$ for alloy 718 at temperatures of $600-650^{\circ} \mathrm{C}$.

It is interesting to compare the present results with previously published studies of the hold-time FCG in Allvac 718Plus. The most comprehensive such investigations has been performed by Liu et al. [4-6]. To be consistent the present results are primarily compared to those obtained on material with grain size ASTM 5 in $[4,5]$.

The FCG rates under purely cyclic loading are similar to those observed in ASTM 5 material tested at $650^{\circ} \mathrm{C}$ and $0.33 \mathrm{~Hz}$ for both as-produced and exposed material, although the crack growth is somewhat faster in the present case. However, contrary to observations in [4, 5], performed at $650^{\circ} \mathrm{C}$ with $100 \mathrm{~s}$ hold-time, an improvement in the hold-time FCG properties due to long-time exposure could not be observed in the present case. Here, the exposed material showed similar FCG rates under purely cyclic loading, but during the 90 s hold-time blocks at both $600^{\circ} \mathrm{C}$ and $700^{\circ} \mathrm{C}$ the FCG rate increased compared to the as-heat treated material. Liu et al. $[4,5]$ reported a reduction in hold-time FCG of roughly one order of magnitude when Allvac 718 Plus (in material which had not been subjected to pre-solution soaking) was exposed at $760^{\circ} \mathrm{C}$ for $350 \mathrm{~h}$. 
Overall, the hold-time FCG rate in the as-produced condition is lower in the present case compared to Liu et al., whereas the observed propagations rates are higher for the exposed material. The relative increase in FCG rate due to the hold-times is actually smaller in the present investigation, especially in the as-produced condition. Liu et al. also tested specimens subjected to the same pre-solution soaking as in the present investigation and found beneficial effects on the hold-time FCG behavior (FCG rates intermediate between the as-produced and exposed curves in the present investigation) $[4,5]$.

The present exposure treatment has lower temperature $\left(140 \mathrm{~h}\right.$ at $700^{\circ} \mathrm{C}+460 \mathrm{~h}$ at $\left.675^{\circ} \mathrm{C}\right)$ than that of Liu et al., which will influence the extent of the possible microstructual changes. The observed effects from of long-term exposure at $760^{\circ} \mathrm{C}$ are precipitate coarsening and transformation of hardening precipitates to $\delta$-phase $[15,16]$. The observed effects of $350 \mathrm{~h}$ exposure at $760^{\circ} \mathrm{C}$ in $[15,16]$ was an increase in the $\gamma^{\prime}$ size, from 20 to $50 \mathrm{~nm}$ with a roughly constant volume fraction, and an increased fraction of $\delta$-phase, from 1 to $3 \%$. As the exposure temperature of $760^{\circ} \mathrm{C}$ in $[4,5,15,16]$ is not expected to produce other phases compared to the present case, the main difference between the two exposures is expected to be the extent of these changes. Consequently, the present exposure could be expected to produce similar effects on the mechanical properties as in $[4,5]$ but to a lesser extent. The slight increase in room temperature hardness after exposure (from 437 to $450 \mathrm{HV} 10$ average) could be an indication that the effect of the exposure treatment is mainly to produce an additional hardening. This is presumably achieved by growth of $\gamma$ ' precipitates to a size closer to the optimum. As the exposure temperature is relatively low (below the recommended maximum operating temperature of $704^{\circ} \mathrm{C}$ ) the coarsening process is slow and the structure is not over-aged. The observed increase in hardness is consistent with tensile tests results on material from the same ring in as-produced and exposed condition where the exposure resulted in an increase in both yield- and ultimate tensile strength, especially at elevated temperatures [17]. Cao, on the other hand, reported reductions in the strength of Allvac 718 Plus after exposure at $760^{\circ} \mathrm{C}$ [15]. Thus there seem to be a significant effect of the choice of exposure temperature on the response of the material.

The actual features controlling the susceptibility to hold-time fatigue crack growth are not clear at present. Increased resistance is commonly attribute to the presence of $\delta$-phase at the grain boundaries, but recent studies of the effect of microstructural features on the stress rupture properties of Allvac 718Plus [8,9] have indicated that grain boundary $\delta$ plays a minor role for the behavior at $704^{\circ} \mathrm{C}$. The main difference between susceptible and resistant microstructures in [9] was the presence of subgrains and dislocation substructures in the grain interiors in the material with high resistance to grain boundary cracking. It was suggested that these substructures compete with the grain boundaries for oxygen, thus reducing the concentrations at the grain boundaries. Previous results on Allvac 718Plus sheet material with clean grain boundaries (i.e. no grain boundary $\delta$ ), on the other hand, has shown that the absence of precipitates in the grain boundaries results in significantly higher hold-time crack growth rates [7]. This could indicate that the presence of $\delta$ phase in the boundaries is beneficial, but the volume fraction and morphology is less important. However, this requires further studies of the interactions between the crack and the precipitates during intergranular crack growth. Additionally, the crack was shown to propagate along high-angle grain boundaries but not along the numerous special $(\Sigma 3)$ boundaries present in the material [9]. This is consistent with the work by Krupp et al. $[18,19]$ where it was shown that thermo-mechanical processing which resulted in 
a high fraction of special boundaries significantly decreased the sustained load crack propagation rate in Inconel 718.
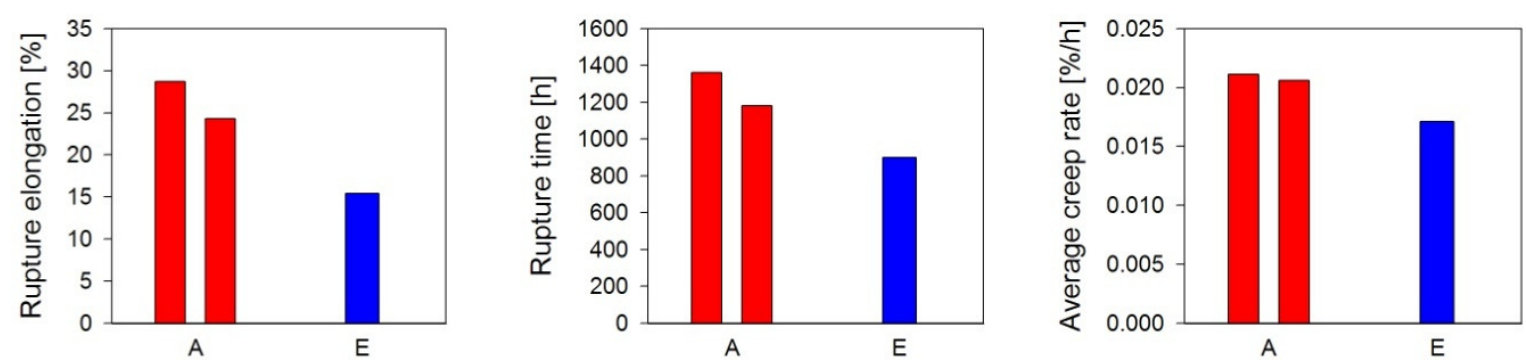

Figure 10. Stress rupture tests of Allvac 718Plus in the A end E condition at $689 \mathrm{MPa}$ and $649^{\circ} \mathrm{C}$ showing decreased creep ductility and time to rupture. The average creep rate (calculated as rupture elongation divided by time to rupture) decreases.

Furthermore, it has been shown that the creep resistance of the alloy is of primary importance for the response of the material to hold-time fatigue cycles, where a rapid stress relaxation (low creep resistance) is favorable for the resistance to hold-time fatigue crack growth [20, 21]. Also Cao observed an increase in the creep rate, especially during primary creep, and improved holdtime fatigue resistance after exposure [15]. A possible explanation for the beneficial effect of high creep rate is the stress re-distribution around the crack tip and rapid reduction in plastic strain rate which reduces the transport of damaging species. One consequence of this is that also the grain interior plays a major role trough creep property control, even though the actual embrittling and hold time crack growth processes are grain boundary phenomena [22]. The increase in strength with exposure could suggest that also the creep properties are enhanced by the exposure, and this could be the explanation for the reduced hold-time FCG resistance. Stress rupture tests performed on the conditions in this study at $649^{\circ} \mathrm{C}$ showed that the both time to rupture and creep ductility decreased with the long-time exposure treatment (Fig. 10). Calculating the average creep rate as rupture elongation divided by time to rupture shows that the resistance to creep deformation actually increases, even though the creep ductility is reduced. This indicates that the decrease in the hold-time FCG resistance with exposure may be explained by increased creep resistance. However, this requires further studies of the development of the primary creep rate, which should be the controlling factor.

\section{Conclusions}

- No microstructural effects of long-time exposure $\left(700^{\circ} \mathrm{C} / 140 \mathrm{~h}+675^{\circ} \mathrm{C} / 460 \mathrm{~h}\right)$ could be observed by SEM, but there were indications that the hardness of the material increased somewhat after exposure.

- At 600 and $700^{\circ} \mathrm{C}$ the introduction of $90 \mathrm{~s}$ hold-time at maximum load significantly increased the fatigue crack growth rate. Both conditions showed purely cycle dependent behavior at $450^{\circ} \mathrm{C}$ and purely time dependent behavior at $700^{\circ} \mathrm{C}$. At $600^{\circ} \mathrm{C}$ intermediate behavior was observed.

- The long-time exposure had little effect on the cyclic $(0.5 \mathrm{~Hz})$ crack growth rates, but the resistance to crack growth with $90 \mathrm{~s}$ hold-time decreased. Also the creep ductility decreased after exposure but the average creep rate was reduced. 
- The exposure temperature is critical for the effect on the hold-time FCG resistance. Exposure in the range 675 to $700^{\circ} \mathrm{C}$ is detrimental for the hold-time properties, whereas other investigations have shown a beneficial effect of exposure at $760^{\circ} \mathrm{C}$.

\section{Acknowledgements}

The material and mechanical results have been obtained within the VITAL (EnVIronmenTALly friendly aero engines) project, financed by the $6^{\text {th }}$ European Framework Program, which is kindly acknowledged.

\section{References}

1. R. L. Kennedy, W.-D. Cao, T. D. Bayha and R. Jeniski, "Developments in wrought $\mathrm{Nb}$ containing superalloys $\left(718+100^{\circ} \mathrm{F}\right)$," Niobium, High Temperature Applications, Editors Y.W. Kim et al., (2003), 11-22.

2. W.-D. Cao and R. L. Kennedy, "Role of chemistry in 718-type alloys - Allvac 718Plus alloy development," Superalloys 2004, Editors K. A. Green et al., (2004), 91-9.

3. D. A. Woodford, "Gas phase embrittlement and time dependent cracking of nickel base superalloys," Energy Materials, 1 (2006) 59-79.

4. X. Liu, J. Xu, E. Barbero. W.-D. Cao and R. L. Kennedy, "Effect of thermal treatment on the fatigue crack propagation behavior of a new Ni-base superalloy," Materials Science and Engineering A, 474 (2008), 30-38.

5. X. Liu, J. Xu, N. Deem, K.-M. Chang, E. Barbero, W.-D. Cao, R. L. Kennedy and T. Carneiro, "Effect of thermal-mechanical treatment on the fatigue crack propagation behavior of newly developed Allvac 718plus superalloy," Superalloys 718, 625, 706 and Derivatives 2005, Editor E. A. Loria, (2005), 233-242.

6. X. Liu, S. Rangararan, E. Barbero, K.-M. Chang, W.-D. Cao, R. L. Kennedy and T. Carneiro, "Fatigue crack propagation behavior of new developed Allvac 718plus superalloy," Superalloys 2004, Editors K. A. Green at al., (2004), 283-290.

7. L. Viskari, "High temperature cracking of Ni-base superalloys," (Licentiate Thesis, Chalmers University of Technology, 2009).

8. R. Hayes, E. Thompson, K. Johnson and A. Aichlmayr, "Effect of het treatment on the combination stress-rupture properties of Allvac 718Plus," Materials Science and Engineering A, 510-511 (2009) 256-61.

9. K. A. Unocic, R. W. Hayes, M. J. Mills and G. S. Daehn, "Microstructural features leading to enhanced resistance to grain boundary creep cracking in Allvac 718Plus," Metallurgical and Materials Transactions, 41A (2010), 409-20.

10. ASTM E740-03, "Standard practice for fracture testing with surface-crack tension specimens," In Annual Book of ASTM Standards, Volume 03.01, West Conshohocken (PA), ASM International (2004). 
11. ASTM E647-08, "Standard test method for measurement of fatigue crack growth rates," In Annual Book of ASTM Standards, Volume 03.01, West Conshohocken (PA), ASM International; (2004).

12. J. P. Pédron and A. Pineau, "The effect of microstructure and environment on the crack growth behaviour of Inconel 718 alloy at $650^{\circ} \mathrm{C}$ under fatigue, creep and combined loading," Materials Science and Engineering A, 56 (1982) 143-56.

13. F. V. Antunes, J. M. Ferreira, C. M. Branco and J. Byrne, "Influence of stress state on high temperature fatigue crack growth in Inconel 718," Fatigue and Fracture of Engineering Materials and Structures, 24 (2001), 127-135.

14. P. Heuler, E. Affeldt and R. J. H. Wanhill, "Effect of loading waveform and stress field onhigh temperature fatigue crack growth of Alloy 718," Materialwissenschaft und Werkstofftechnik, 34 (2003), 790-796.

15. W.-D. Cao, "Thermal stability characterization of Ni-base ATI 718Plus superalloy," Superalloys 2008, Editor R. C. Reed et al. (2008), 789-97.

16. X. Xie, G. Wang, J. Dong, C. Xu, W.-D. Cao and R. L. Kennedy, "Structure stability study on a newly developed Nickel-base superalloy - Allvac 718Plus," Superalloys 718, 625, 706 and Derivatives 2005, Editor E. A. Loria, (2005), 179-91.

17. T. Gómez-Acebo, A. J. Lopez, J. C. Rodríguez, F. Castro, O. Caballero, M. Goiricelaya, K. Celaya, K. Ostolaza, G. Sjöberg and M. Hörnqvist, "Comparison between the Microstructure and the Mechanical Properties of In718 and 718Plus Alloys after Exposition," To be presented at Superalloys 718, 625, 706 and Derivatives 2005 (2010).

18. U. Krupp, W. M. Kane, X. Liu, O. Deuber, C. Laird and C. J. McMahon, Jr., "The effect of grain-boundary-engineering-type processing on oxygen induced cracking of IN718," Materials Science and Engineering A 349 (2003) 213-7.

19. U. Krupp, P. E.-G. Wagenheuber, W. M. Kane and C. J. McMahon, Jr., "Improving resistance to dynamic embrittlement and intergranular oxidation in nickel based superalloys by grain boundary engineering type processing," Materials Science and Technology, 21 (2005) 1247-54.

20. A. Pineau and S. D. Antolovich, "High temperature fatigue of Nickel-base superalloys - A review with special emphasis on deformation modes and oxidation," Engineering Failure Analysis, 16 (2009), 2668-2697.

21. S. Ponelle, B. Brethes and A. Pineau, "High temperature fatigue crack growth rate in Inconel 718: Dwell effect annihilations," Temperature-Fatigue Interaction (2002), 257-266.

22. A. Pineau, "High temperature fatigue of Ni-base superalloys: Microstructural and environmental effects," Engineering against fatigue (1997), 557-565. 